\title{
Metabolic phenotype in the mouse model of osteogenesis imperfecta
}

\author{
Iris Boraschi-Diaz',2, Josephine T Tauer1, Omar El-Rifai3, Delphine Guillemette1,4, \\ Geneviève Lefebvre4, Frank Rauch1, Mathieu Ferron ${ }^{3,5}$ and Svetlana V Komarova1,2 \\ 1Shriners Hospital for Children-Canada, Montreal, Quebec, Canada \\ 2Faculty of Dentistry, McGill University, Montreal, Quebec, Canada \\ 3Unité de Recherche en Physiologie Intégrative et Moléculaire, Institut de Recherches Cliniques de Montréal, \\ Montréal, Québec, Canada \\ ${ }^{4}$ Département de Mathématiques, Université du Québec à Montréal, Montréal, Québec, Canada \\ ${ }^{5}$ Départements de Médecine et de Biochimie et Médecine Moléculaire, Université de Montréal, Montréal, \\ Québec, Canada
}

Correspondence should be addressed to S V Komarova Email svetlana.komarova@mcgill.ca

\begin{abstract}
Osteogenesis imperfecta (OI) is the most common heritable bone fragility disorder, usually caused by dominant mutations in genes coding for collagen type I alpha chains, COL1A1 or COL1A2. Osteocalcin (OCN) is now recognized as a bone-derived regulator of insulin secretion and sensitivity and glucose homeostasis. Since OI is associated with increased rates of bone formation and resorption, we hypothesized that the levels of undercarboxylated OCN are increased in OI. The objective of this study was to determine changes in OCN and to elucidate the metabolic phenotype in the Col1a1 Jrt/+ mouse, a model of dominant Ol caused by a Col1a1 mutation. Circulating levels of undercarboxylated OCN were higher in 4-week-old OI mice and normal by 8 weeks of age. Young $\mathrm{OI}$ animals exhibited a sex-dependent metabolic phenotype, including increased insulin levels in males, improved glucose tolerance in females, lower levels of random glucose and low adiposity in both sexes. The rates of $\mathrm{O}_{2}$ consumption and $\mathrm{CO}_{2}$ production, as well as energy expenditure assessed using indirect calorimetry were significantly increased in OI animals of both sexes, whereas respiratory exchange ratio was significantly higher in OI males only. Although OI mice have significant physical impairment that may contribute to metabolic differences, we specifically accounted for movement and compared OI and WT animals during the periods of similar activity levels. Taken together, our data strongly suggest that OI animals have alterations in whole body energy metabolism that are consistent with the action of undercarboxylated osteocalcin.
\end{abstract}
Key Words
- glucose homeostasis
- indirect calorimetry
- metabolism
- osteogenesis imperfecta
- undercarboxylated osteocalcin

\section{Introduction}

Osteogenesis imperfecta $(\mathrm{OI})$ is the most common heritable bone fragility disorder (prevalence 1:10,000), leading to recurrent fractures and bone deformities. Approximately, $85 \%$ of individuals with OI have dominant mutations in one of the two genes that code for collagen type I alpha chains, COL1A1 and COL1A2 (Forlino et al. 2011). Our clinical studies have demonstrated that children with OI, including the mildest forms, have slow growth and 
low muscle mass, which remain largely unexplained and untreated to date (Zeitlin et al. 2003, Pouliot-Laforte et al . 2014, Veilleux et al. 2015, Palomo et al. 2016).

Osteocalcin $(\mathrm{OCN})$ is now recognized as a bone-derived regulator of glucose homeostasis (Fulzele \& Clemens 2012, Karsenty \& Ferron 2012). It is produced by osteoblasts and deposited in bone matrix in a $\gamma$-carboxylated form (Ducy et al. 1996). During bone resorption, osteoclasts release and partially decarboxylate $\mathrm{OCN}$, generating an active undercarboxylated form (Ferron et al. 2010a, 2015, Lacombe et al. 2013). OCN influences glucose metabolism through regulation of both insulin secretion and sensitivity (Lee et al. 2007, Ferron et al. 2008). OCN leads to decrease in adiposity and increase in adiponectin production by fat cells, also contributing to increased insulin sensitivity (Ferron et al. 2008). In addition, it was recently demonstrated that $\mathrm{OCN}$ promotes adaptation to exercise by increasing glucose uptake and free fatty acid oxidation in muscle cells (Mera et al. 2016). Bone histomorphometric studies have shown that children and adolescents with OI have increased rates of bone formation and resorption (Rauch et al. 2000, 2010). Similarly, several mouse models of OI, including Brtl, oim/oim and Col1a1 $1_{\mathrm{rrt} /+}$, have elevated osteoclast numbers and bone resorption rates (Kalajzic et al. 2002, Uveges et al. 2008, Roschger et al. 2014). Therefore, we hypothesized that the level of active, undercarboxylated, OCN is increased in OI, affecting energy metabolism, which may in turn contribute to growth and muscle deficits.

The goal of this study was to examine the OCNdriven endocrine disturbances in the Col1a1 Jrt/+ mouse model of OI (Chen et al. 2014). In this model, a T to C transition at the exon 9 splice donor site of Col1a1 results in the skipping of exon 9, and an 18 amino acid deletion in the triple helical domain of the collagen type I alpha 1 chain. Col1a1 $1^{\mathrm{Jr} /+}$ mice are smaller in size and have lower bone mineral density, decreased bone volume/tissue volume, and weaker, more brittle bones than their wild type (WT) littermates (Chen et al. 2014, Roschger et al. 2014). The Col1a1 ${ }^{\mathrm{Irt} /+}$ mouse has spontaneous fractures and deformities (Kozloff et al. 2004, Daley et al. 2010, Chen et al. 2014, Abdelaziz et al. 2015), and has a more severe bone fragility phenotype than other OI models with dominant mutations, such as the Brtl mouse and the 'Amish mouse' (Kozloff et al. 2004, Daley et al. 2010).

This study focused on characterizing OCN levels, glucose and insulin homeostasis, metabolic parameters including energy expenditure (EE) as well as adipose tissue phenotype in Col1a1 Jrt/+ (OI) animals compared to WT. As OI is a developmental disease evident and treated in pediatric patients, we used young 4-week-old animals.

\section{Materials and methods}

\section{Animals}

All experiments were approved by the Animal Care Committee at the McGill University and conformed to the ethical guidelines of the Canadian Council on Animal Care. The Col1a1Jrt/+ mice on a FVB background, developed by screening of N-ethyl-N-nitrosourea-induced mutagenesis (Chen et al. 2014) were a gift from Dr Jane Aubin's laboratory, University of Toronto. The breeding colony was maintained at the Animal Care Facility of the Shriners Hospitals for Children-Canada. Animals were on a 12-h alternating light and darkness cycle and had unrestricted access to water and food (Charles River rodent diet 5075, USA). Weekly, 4-12 weeks old animals were weighted and the measurements of body length (between nose and base of the tail) were taken using a ruler.

\section{DXA analysis}

It was performed in the Centre for Bone and Periodontal Research, McGill University, using a GE Lunar PIXImus in an area of imaging of $100 \times 80 \mathrm{~mm}$, with a focal spot of $0.25 \times 0.25 \mathrm{~mm}$, using energy of $80 \mathrm{kV}$ and current of $400 \mu \mathrm{A}$.

\section{EchoMRI}

It was performed at the McGill Mouse Metabolic Platform on live animals using EchoMRI model ET-040, version 11,06,22 (EchoMRI LLC).

\section{Microcomputed tomography (micro CT)}

It was performed on right femurs of 4-week-old mice using Skyscan 1272 at a voxel size of $5 \mu \mathrm{m}$. Scan parameters included a 0.40 -degree increment angle, 3 frames averaged, a $62 \mathrm{kV}$ and $161-\mathrm{mA}$ X-ray source with a $0.5-\mathrm{mm}$ Al filter to reduce beam-hardening artifacts. Trabecular bone was manually selected along the inner cortical surface. Scans were quantified using the system's analysis software (Skyscan CTAnalyser, Version 1.16.1.0). To analyze cortical bone, scanning was performed starting 
at a distance of $44 \%$ of the total femur length from the distal end and scanned for $1 \mathrm{~mm}$ proximally. Average outer bone diameter and average diameter of the bone marrow cavity were determined from cross-sectional areas assuming a circular bone cross-section. Cortical thickness was calculated as the difference of these two diameters divided by 2 .

\section{Three-point bending test}

Following microCT scanning, right femora were loaded to failure in three-point bending using a Materials Testing System Model 5943 (INSTRON, Norwood, MA, USA). The distance between the lower supports was $7 \mathrm{~mm}$ with a vertical displacement rate of $50 \mu \mathrm{m} / \mathrm{s}$. The anterior middiaphysis was loaded under tension and the tests were analyzed using the system's analysis software Bluehill (Illinois Tool Works Inc., Glenview, IL, USA; Version 3.65).

\section{C-telopeptide of collagen type I (CTX)}

CTX was quantified in serum samples of non-fasted animals by enzyme-linked immunosorbent assay (ELISA) (Ratlaps (CTX-I) EIA, Ref AC-06F1, Immunodiagnostic Systems).

\section{Tissue analysis}

Upon dissection, the weight of inguinal subcutaneous white fat pad, interscapular brown fat pad, liver, spleen and pancreas weights were assessed.

\section{GLU, GLA13 and total mouse osteocalcin ELISA}

GLU, GLA13 and total mouse osteocalcin ELISA were measured in non-fasted serum using a triple ELISA system as described previously (Ferron et al. 2010b). Briefly, antibody coating buffer (CB1), ELISA wash buffer (WB1), general blocker buffer (BB1), general assay diluent (AD1) and stop solution for TMB (STOP1) were all obtained from ImmunoChemistry Technologies. 1-Step Ultra TMB ELISA substrate was from Pierce. ELISA plates (R\&D system) were coated overnight at room temperature with affinity purified anti-GLU-OCN, anti-GLA13-OCN or anti-MIDOCN diluted in antibody coating buffer. Following 2 washes with wash buffer, the plate was blocked with $300 \mu \mathrm{L}$ of general blocker buffer for 3-6h at room temperature, blocking solution was removed, and the plate was used immediately. $95 \mu \mathrm{L}$ of general assay diluent was added to each well, followed by $5 \mu \mathrm{L}$ of blank standards (purified
GLU-OCN or synthetic GLA-OCN) or diluted serum samples. Plate was sealed and incubated overnight at $4^{\circ} \mathrm{C}$. Following 5 washes, $100 \mu \mathrm{L}$ of HRP-conjugated anti-CTOCN $(1 \mu \mathrm{g} / \mathrm{mL}$ in general assay diluent) was added and the plate was incubated for $1 \mathrm{~h}$ at room temperature on a shaker ( 200-300 rpm). After 5 washes, $100 \mu \mathrm{L}$ of TMB substrate was added, the plate was incubated for $15 \mathrm{~min}$ at room temperature, then $100 \mu \mathrm{L}$ of stop solution was added and the absorbance at $450 \mathrm{~nm}$ was read using a plate reader (Biorad). Concentrations of GLU-OCN, GLA13OCN and total OCN in the samples were calculated from polynomial second order or exponential standard curve obtained from the standard included in each assay. GLU13 was calculated by subtracting GLA13 from total.

\section{Glucose and insulin measurements}

Glucose levels were measured in the whole blood using strips with the ONETOUCH Ultra2 glucometer (Johnson \& Johnson). Insulin levels were measured in non-fasted serum using ELISA (Cristal Chem 90080, and Mercodia 10-1247-10). Prior to blood collection for fasting glucose levels and glucose tolerance test (GTT), the food was withdrawn for $5 \mathrm{~h}$ for 4 -week-old animals and for $16 \mathrm{~h}$ for mice older than 6-weeks. Prior to insulin tolerance test (ITT), the food was withdrawn for $5 \mathrm{~h}$. For GTT and ITT blood glucose was measured in samples from tail tip immediately before (time 0 ) and 15, 30, 60, 90, and $120 \mathrm{~min}$ after intraperitoneal injection of $2 \mathrm{~g} / \mathrm{kg}$ glucose for GTT or $0.6 \mathrm{U} / \mathrm{kg}$ insulin for ITT.

\section{Indirect calorimetry}

Indirect calorimetry was performed at the McGill Mouse Metabolic Platform. The animals were housed in the LabMaster/PhenoMaster system (TSE Systems, Germany), which allows to measure the following outcomes in 16 parallel cages: (1) Locomotor activity via sensor frames based on infrared beam breaking; (2) Amount and temporal pattern for food and water intake; (3) $\mathrm{O}_{2}$ consumption $\left(\mathrm{VO}_{2}\right)$ and $\mathrm{CO}_{2}$ production $\left(\mathrm{VCO}_{2}\right)$ via indirect calorimetry; and (4) Calculated EE and substrate utilization from the assessment of $\mathrm{VO}_{2}$ and $\mathrm{VCO}_{2}$.

\section{RNA isolation, qRT PCR}

Total RNA was isolated from bone with the RNeasyMini Kit (Qiagen Inc.:74106). RNA and cDNA concentration were quantified with the Quant-iTTM instrument

Published by Bioscientifica Ltd. 
(Invitrogen: Q32860). Reverse transcription of $0.75 \mathrm{ng}$ RNA was performed using the High Capacity cDNA Reverse Transcription Kit (Applied Biosystems, Thermo Fisher Scientific). Real-time PCR was performed using a 7500 Applied Biosystems Instrument, the Wisent Advance qPCR master mix with Supergreen dye (800-431-UL, Wisent, St-Bruno, QC, Canada) and the following primers were used: Bglap1/2 Fwd (CAGACAAGTCCCACACAGCA), Bglap1/2 Rv (CTTGGCATCTGTGAGGTCAG). Gapdh Fwd (CAAGTATGATGACATCAAGAA) and Gapdh Rv (GGAAGAGTGGGAGTTGCTGT) were used as the endogenous control.

\section{Cluster analysis}

From the indirect calorimetry data, we used locomotor activity and amount of food and water intake to identify groups of observations that are similar to each other using clustering with the Ward's method (Ward 1963). First, we used data from 16 mice containing both sexes and genotypes to identify the number of clusters within the dataset. Next, classification analysis was developed to assign an observation period to one of a known number $(k)$ of predefined clusters. For this, we the used quadratic classification function:

$$
D_{j}^{2}(y)=\left(y-\bar{y}_{j}\right)^{T} S_{j}^{-1}\left(y-\bar{y}_{j}\right)
$$

which allowed us to calculate:

$$
Q_{j}(y)=\ln \left(p_{j}\right)-\frac{1}{2} \ln \left(\left|S_{j}\right|\right)-\frac{1}{2} D_{j}^{2}(y)
$$

where $\bar{y}_{j}, S_{j}$ and $p_{j}$ are the sample mean, covariance matrix and proportion of the $j$ th cluster, respectively. Then, the classification rule assigns the observation period to the cluster $j$ for which $Q j(y)$ is the largest. Cluster analysis was performed in Rstudio version 0.99.489.

\section{Statistical analysis}

Data are expressed as means \pm S.E.M., with $n$ indicating number of animals, $P<0.05$ was considered statistically significant. Two-way ANOVA was used for comparing the effect of genotype over time. Student $t$-test was used to compare between two groups at a single time point. Threeway ANOVA was used to examine sexual dimorphism. Statistical analyses were performed using MATLAB (The MathWorks Inc.).

\section{Results}

Previously, the Col1a1 $1^{\mathrm{Jr} / \mathrm{+}}$ mouse model was studied at 8-24 weeks of age, which corresponds to the young adult stage in human development (Chen et al. 2014, Roschger et al. 2014, Abdelaziz et al. 2015). We now analyzed the bone phenotype in 4-week-old OI mice,
A

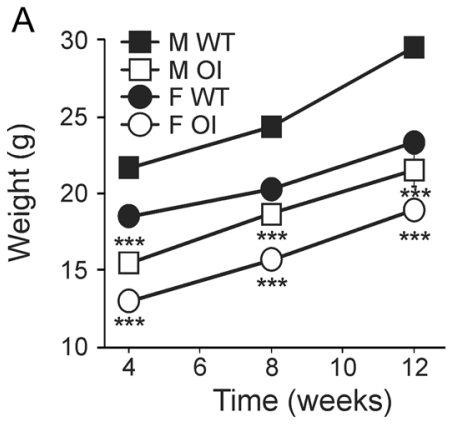

B

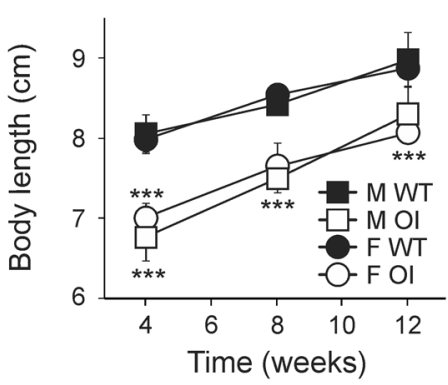

D

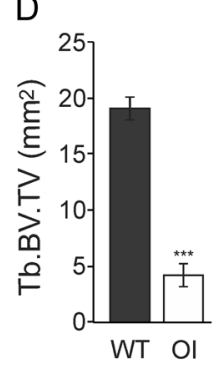

E

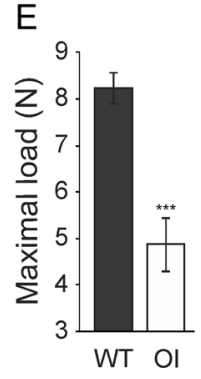

$\mathrm{F}$

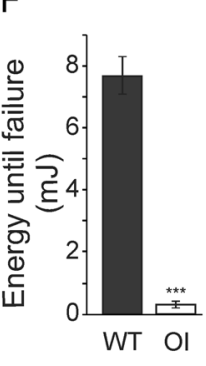

Figure 1

Skeletal phenotype of 4-week-old Ol (Col1a $1^{\mathrm{Jrt} /+}$ ) mice. (A and $B$ ) Weight gain $(A)$ and linear growth (B) in Ol mice, $n=8-12$ animals per time point/ genotype/sex. (C and D) Representative micro CT images (C) and quantification (D) of trabecular bone density as bone volume over total volume (Tb.BV.TV) of WT and OI right femora. (E and F) Average maximal load ( $E$ ) and energy until failure (F) for WT and OI femora assessed using three-point bending method, $n=4$ male animals/ genotype. Data are means \pm S.E.M., significance was examined by two-way ANOVA with Bonferroni post-test for $A, B$, and by Student $t$-test for $\mathrm{D}, \mathrm{E}$ and $\mathrm{F} .{ }^{*} P<0.05, * * P<0.01$, $* * * P<0.001$ for the effect of genotype for the same age/sex. 

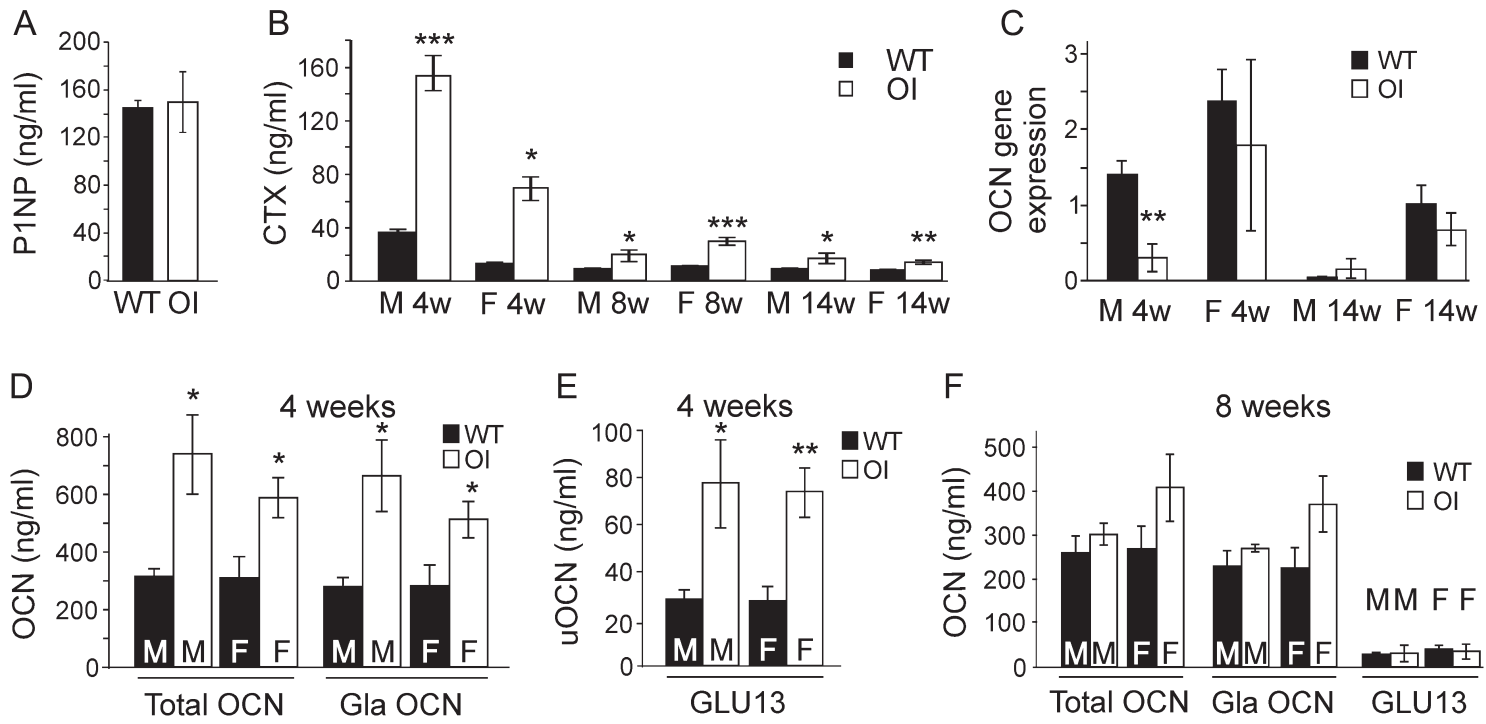

Figure 2

The circulating levels of OCN in OI mice. (A and B) Serum levels of P1NP (A) in 4-week-old, $n=4$ male animals/genotype and CTX (B) in 4 ( $n=6), 8(n=8)$ and 14-week-old $(n=4)$ OI and WT mice. (C) Relative expression of OCN gene Bgla1/2 in bones of OI and WT mice, $n=3-5$. (D and E) Total and carboxylated (Gla) OCN (D) and undercarboxylated (GLU13) OCN (E) in 4-week-old OI and WT mice. (F) Total OCN, Gla and GLU13 OCN in 8-week-old mice. For $\mathrm{D}, \mathrm{E}$ and $\mathrm{F}, n=4$ animals/genotype/sex except for female Ol where $n=3$. Data are means \pm s.E.M., ${ }^{*} P<0.05 ;{ }^{*} P<0.01 ;{ }^{* *} P<0.001$ for the effect of genotype by Student $t$-test.

which is similar to the pre-pubertal stage in human development (Fig. 1). Both male and female OI animals present significant deficits in weight (Fig. 1A) and linear growth (Fig. 1B). Similar to older animals (Chen et al. 2014), young OI mice have significant reduction in bone density (Fig. 1C and D). Bone structural properties were
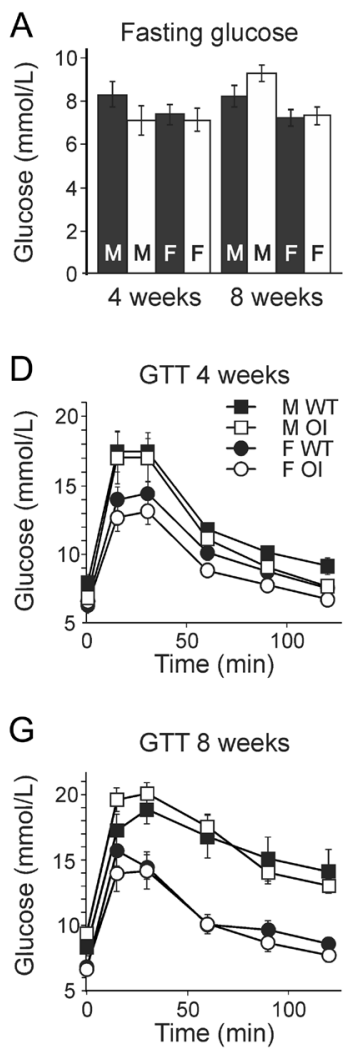
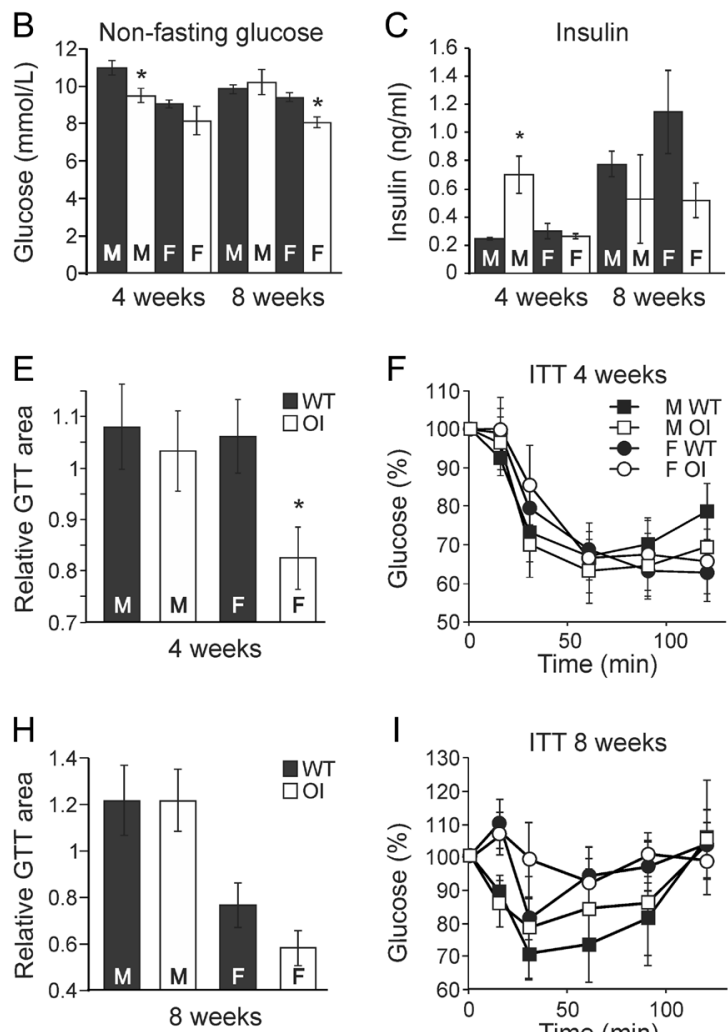
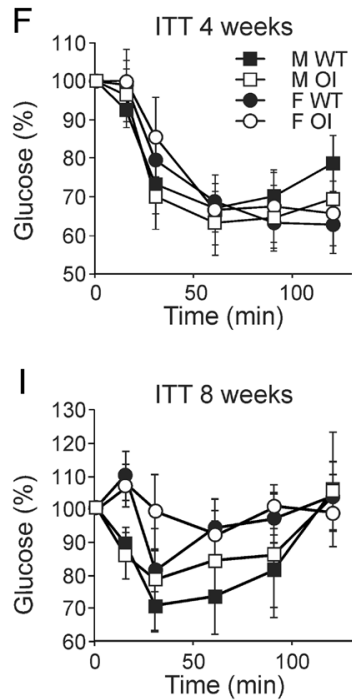

Figure 3

Glucose and insulin levels and tolerance in $\mathrm{OI}$ mice. ( $A, B$ and $C$ ) Average levels of fasting ( $A, n=9-16$ animals) and random (B, $n=10-18)$ glucose and insulin (C, $n=3-4)$ in 4 and 8-weekold animals, $* P<0.05$ by Student $t$-test. (D, E and F) GTT (D), area under the GTT curve (E) and ITT $(F)$ in 4-week-old animals, $n=9-16$. For $D$ genotype had significant effect $(P<0.01)$ for female mice by two-way ANOVA, for $E * P<0.05$ by Student $t$-test. (G, H and I) GTT (G), area under the GTT curve $(\mathrm{H})$ and ITT (I) in 8-week-old animals, $n=8-12$, no significant difference. Data are means \pm S.E.M. 
significantly compromised in OI mice as evident in threepoint bending testing, which demonstrated significant reduction in maximal load, and energy until failure in young OI mice (Fig. 1E and F).

We hypothesized that in OI active bone resorption results in release of undercarboxylated active OCN. Bone formation marker P1NP was similar in 4-week-old OI and WT mice, but the bone resorption marker CTX was significantly higher in OI animals (Fig. 2A and B). The magnitude of the CTX increase was highest in 4-weekold OI mice. In older mice, CTX remained elevated in OI mice, but to a lesser extent (Fig. 2B). Although expression of the OCN genes, Bgla1/2, was similar or low in OI mice (Fig. 2C), the circulating levels of total, carboxylated and undercarboxylated OCN were significantly higher in 4-week-old OI mice compared to their WT littermates (Fig. 2D and E). Importantly, OCN was increased only in young, actively growing animals, whereas OCN levels were similar in OI and WT animals aged 8 weeks (Fig. 2F).

We next examined if increased levels of undercarboxylated $\mathrm{OCN}$ are associated with changes in glucose metabolism in OI (Fig. 3). Fasting glucose levels were similar in 4- and 8- week-old OI and WT mice (Fig. 3A), however random glucose levels were significantly lower in 4-week-old male OI animals and 8-week-old female OI animals (Fig. 3B). Insulin levels were significantly higher in 4-weeks-old male OI mice, but not significantly different in 8-week-old animals (Fig. 3C). The glycemic excursion during the GTT was significantly smaller in female, but not in 4-week-old OI male mice compared to WT (Fig. 3D), resulting in a significantly lower area under the GTT curve (Fig. 3E). Insulin sensitivity, as assessed by ITT, was similar in 4-week-old OI and WT mice (Fig. 3F). GTT and ITT kinetics were comparable in 8-week-old OI and WT mice (Fig. 3G, H and I).

Indirect calorimetry was used to examine $\mathrm{EE}$ and substrate utilization through the assessment of $\mathrm{O}_{2}$ consumption $\left(\mathrm{VO}_{2}\right)$ and $\mathrm{CO}_{2}$ production $\left(\mathrm{VCO}_{2}\right)$. In addition, we analyzed locomotor activity via sensor frames based on infrared beam breaking as well as food and water intake. Consistent with disease-associated physical impairment, OI animals moved significantly less that WT (Fig. 4A). In addition, 4-week-old OI and WT animals did not differ in food consumption (Fig. 4B) and consumed significantly more water (Fig. 4C) per lean mass compared to WT. To account for a decreased mobility in OI, we performed a cluster analysis using Ward's method, and developed a classification algorithm for all data points for
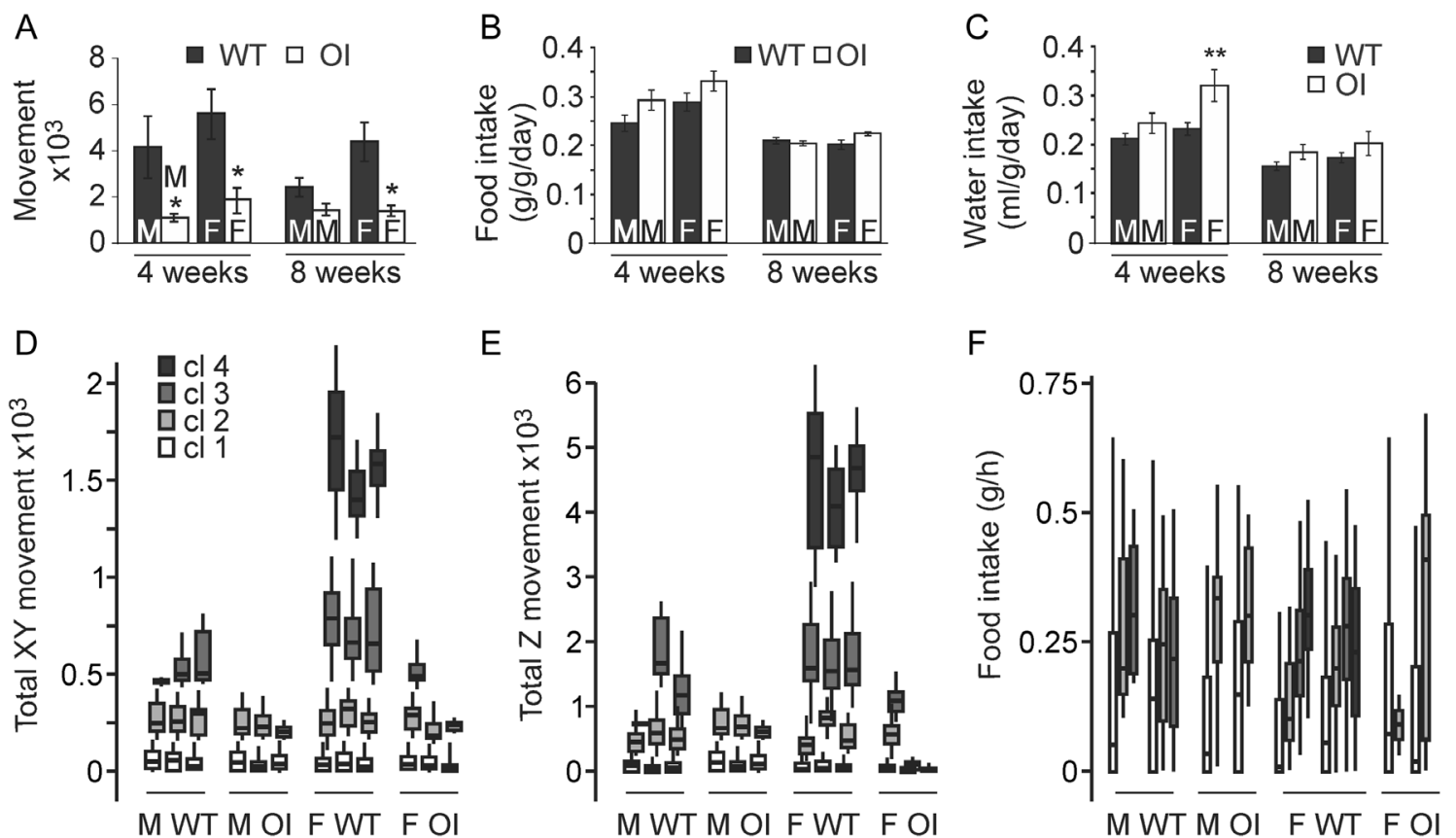

\section{Figure 4}

Movement and nutrition in OI mice. (A) Average number of times a mouse breaks X-beam per hour. (B and C). Average food (B) and water (C) intake per day, normalized to lean body weight. Data are means \pm S.E.M., $n=3-6,{ }^{*} P<0.05$ for the effect of genotype by Student $t$-test. (D, E and F) Classification examples for separating 120 1-h data points for individual 4 weeks old male and female Ol and WT mice into 4 clusters combining observation periods during which animals engage in similar movement in XY plane (D) and Z-plane (E), as well as food intake (F). In the box-plots, the limits of the box indicate the 25th (Q1) and 75th (Q3) percentiles, thick line indicates sample median, the lower whisker is positioned at Q1 - 1.5 (Q3 - Q1) and upper whisker is at $Q 3+1.5(Q 3-Q 1)$. 
A
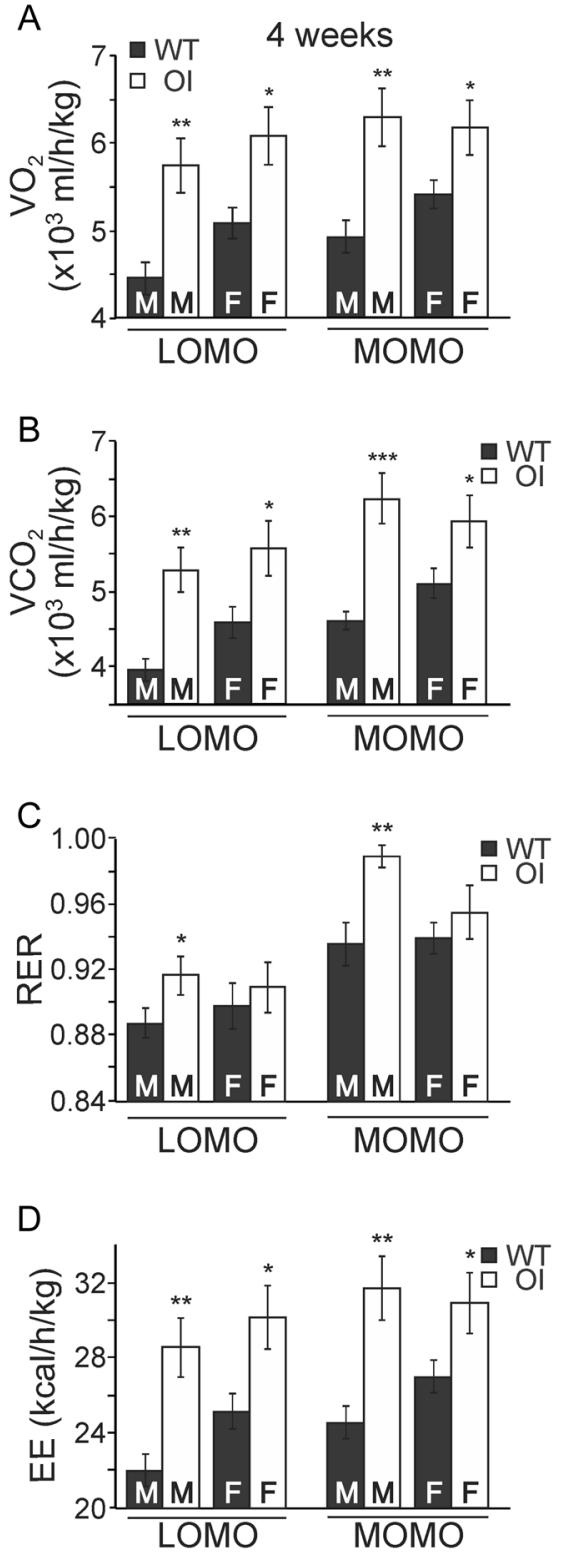

E

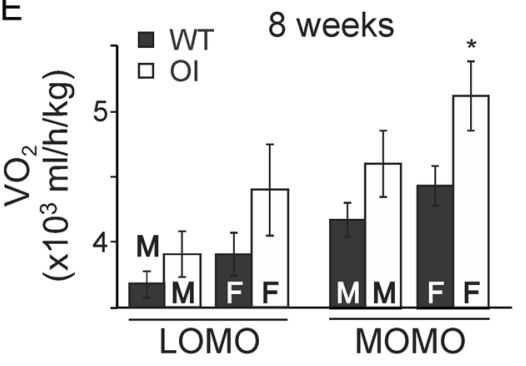

$\mathrm{F}$

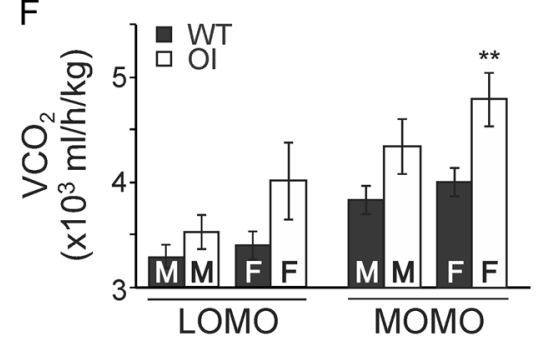

G

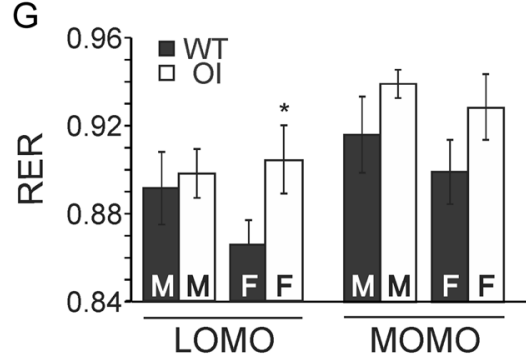

$\mathrm{H}$

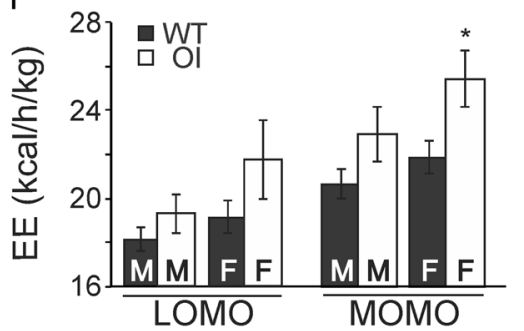

Figure 5

Metabolic profile of OI mice. Animals were studied in TSE Systems metabolic cages. For each mouse, the measures for $1 \mathrm{~h}$ periods of low mobility (LOMO), corresponding to cluster 1 by classification analysis, and moderate mobility (MOMO) corresponding to cluster 2, were averaged. ( $\mathrm{A}$ and $\mathrm{E}) \mathrm{VO}_{2}$ at 4 weeks $(\mathrm{A})$ and 8 weeks (E). (B and $\mathrm{F}$ ) $\mathrm{VCO}_{2}$ at 4 weeks (B) and 8 weeks (F). (C and G) RER at 4 weeks (C) and 8 weeks (G). (D and H) EE at 4 weeks (D) and 8 weeks $(\mathrm{H})$. Data are means \pm S.E.M., for $\mathrm{VO}_{2}$, $\mathrm{VCO}_{2}$ and EE normalized to weight, $n=4-7$ animals, $* P<0.05 ; * * P<0.01$ indicate effect of genotype for the same sex by Student $t$-test. individual animals to identify time periods in which OI and WT mice exhibited similar mobility and food intake. Four clusters were evident (Fig. 4D and F). Periods with the lowest and moderate mobility levels were present in all animals, whereas high mobility was only evident in WT animals, and only female WT mice exhibited the highest mobility. The movement and food intake during the activity periods in clusters 1 (low mobility) and 2 (moderate mobility) were comparable between OI and WT animals, and were used for further analysis.

At 4 weeks of age, both male and female OI animals consumed more $\mathrm{O}_{2}$ and produced more $\mathrm{CO}_{2}$ per body weight compared to WT during the low and moderate movement periods (Fig. 5A and B). Respiratory exchange rate (RER, the ratio of $\mathrm{VCO}_{2}$ to $\mathrm{VO}_{2}$ ), which indicates predominant fuel source: at RER of 0.70 predominate source is fat, while at RER of 1 energy comes from carbohydrates. For both sexes/genotypes RER was lower at low activity and increased during the moderate activity period. Male OI animals had significantly higher RER than WT, whereas female OI and WT animals had similar RER (Fig. 5C). EE calculated based on the respiratory rates was higher in OI mice of both sexes compared to WT (Fig. 5D). At 8 weeks of age, only female OI animals maintained increased $\mathrm{VO}_{2}$ (Fig. 5E), $\mathrm{VCO}_{2}$ (Fig. 5F) and EE (Fig. 5H).

Examination of body composition by EchoMRI demonstrated significantly decreased adiposity of
(C) 2017 Society for Endocrinology Printed in Great Britain 

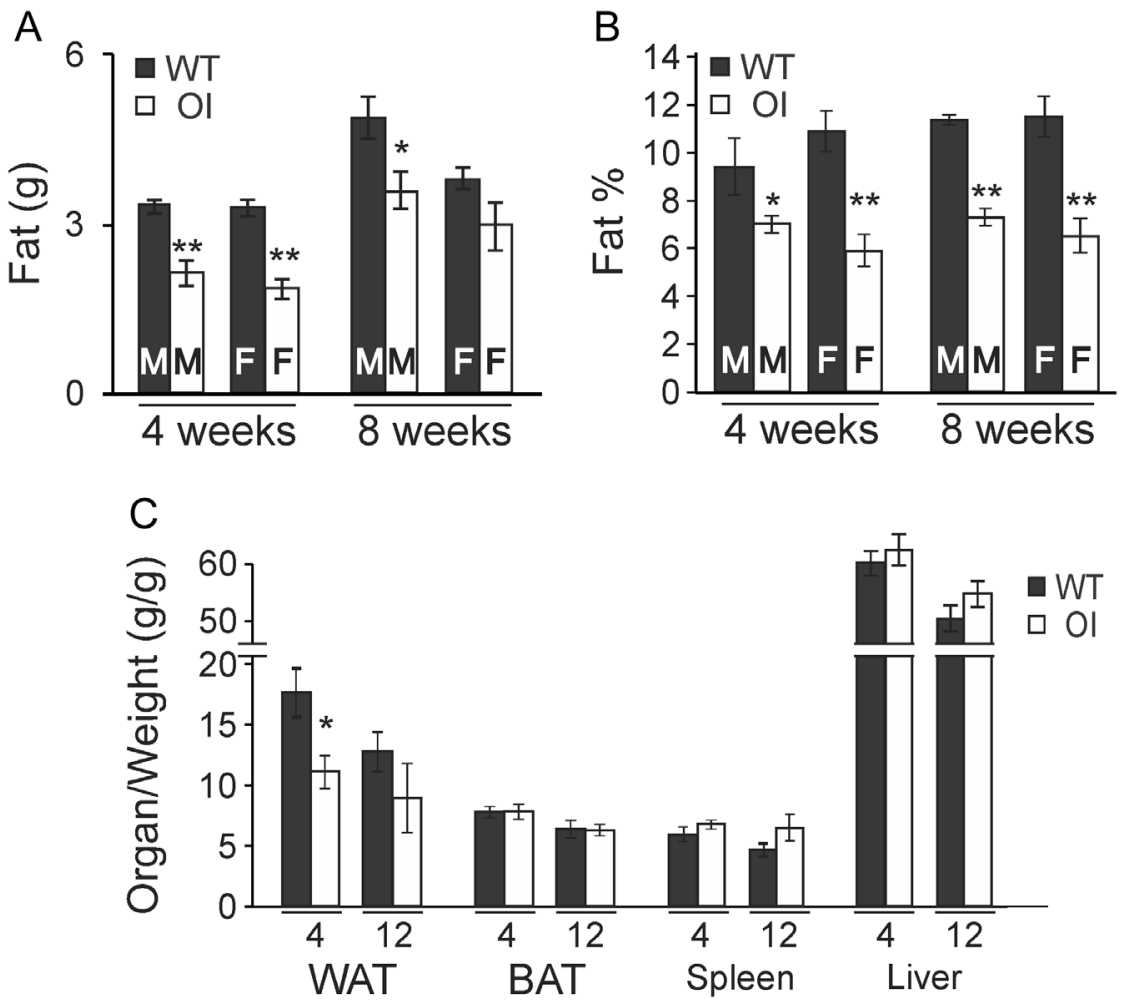
Figure 6
Adipose tissue in OI. (A) Fat mass measured using EchoMRI. (B) Fat percentage calculated using DXA. (C) Relative organ weight for 4-week and 12 week male mice. Data are means \pm s.E.M., $n=3-8, * P<0.05, * * P<0.01$ indicate effect of genotype for the same age/sex.

4-week-old male and female OI animals (Fig. 6A). Similarly, DXA revealed reduced proportion of fat tissue in OI (Fig. 6B). Consistent with EchoMRI and DXA, inguinal subcutaneous deposits of white adipose tissue (WAT) were significantly lower in 4-week-old OI mice, whereas relative weight of brown adipose tissue (BAT), spleen and liver were similar in OI and WT mice (Fig. 6C).

Three-way ANOVA, where the first factor was sex, the second factor was genotype and the third factor was age, revealed that while among anatomical parameters only weight was significantly affected by sex and demonstrated significant interactions between sex and genotype, almost all the parameters of glucose homeostasis were significantly affected by sex, including fasting and random glucose levels, GTT, $\mathrm{VO}_{2}$ and EE.

\section{Discussion}

In this study, we have found that OI animals have a metabolic phenotype, which is age- and sex-dependent. OCN was found to be higher at 4 weeks of age, which corresponds to pre-pubertal growth in humans, and to normalize by 8 weeks of age. Consistent with known effects of OCN, we observed increase in insulin levels in OI males, and improved glucose tolerance in OI females, lower levels of random glucose and a significant decrease in adiposity in OI compared to WT. We have found that rates of $\mathrm{O}_{2}$ consumption and $\mathrm{CO}_{2}$ production, as well as EE were significantly increased in OI animals of both sexes, whereas RER was significantly increased in OI males only. It is important to note that while significant physical impairment is present in OI mice and may potentially contribute to metabolic differences, we specifically accounted for movement and compared OI and WT animals during the periods when they exhibited similar levels of activity. Taken together, our data suggest that alterations in whole body energy metabolism may contribute to OI pathophysiology.

The first question raised by these finding is how does mutation in collagen type I leads to changes in energy utilization and expenditure. Collagen type I mutation is known to lead to increase in osteoblast activity both in humans and in animal models (Kalajzic et al. 2002, Li et al. 2010, Chen et al. 2014). Moreover, it has been long observed that osteoclastic bone resorption is also significantly increased in OI children and animals (Uveges et al. 2008, Cheung et al. 2009, Roschger et al. 2014). Increase in RANKL/OPG ratio may underlie increased osteoclastogenesis in OI, as it has been shown that RANKL is increased in oim osteoblasts (Li et al. 2010) and in children with OI (Brunetti et al. 2016). However, in 
another mouse model of OI, Brtl, RANKL/OPG ratio was reported to be normal, even though the absolute levels of RANKL and OPG were increased (Uveges et al. 2008). It has been shown that the production of Glu13-OCN, a hormonally active form of OCN, requires osteoclastic activity (Ferron et al. 2010a, Lacombe et al. 2013). Consistently, we demonstrate that circulating Glu13OCN levels, but not Bgla1/2 gene expression, are increased in OI animals. Of interest, increased circulating levels of OCN were previously shown in $\mathrm{Brtl}^{/+}$mouse model (Sinder et al. 2015) and in children with OI, in particular with OI type 3, 4 (Brunetti et al. 2016). Although only total OCN levels were measured in those studies, we now demonstrate that in Col1a1 ${ }^{\mathrm{Jt} t /+}$ animals the increase in hormonally active Glu-13-OCN was accompanied by a proportional increase in total and carboxylated OCN. We also demonstrate that both the osteoclast resorption marker CTX and the level of circulating OCN decrease with age in OI mice. Thus, we suggest that collagen type I mutation leads to an increase in production of OCN by osteoblasts, as well as an increase in OCN activation by stimulated osteoclasts, consequently resulting in higher levels of circulating undercarboxylated OCN.

We describe significant alterations in energy homeostasis in OI mice compared to WT, including lower glucose levels, higher insulin levels in males and improved glucose tolerance in females, increase in oxygen consumption and $\mathrm{CO}_{2}$ production, higher EE and lower adiposity. These changes are consistent with known effects of elevated undercarboxylated OCN. OCN has been demonstrated to influence glucose metabolism through regulation of insulin: $\mathrm{OCn}^{-/-}$mice have increased random glucose and decreased insulin circulating levels and are glucose intolerant compared to WT (Lee et al. 2007), whereas injection of $\mathrm{OCN}$ in male WT mice reduced blood random glucose and increased insulin secretion and improved glucose tolerance (Ferron et al. 2008). Decrease in OCN was shown to be associated with decrease in $\mathrm{VO}_{2}$ and $\mathrm{VCO}_{2}$ as well as EE (Ferron et al. 2010a), whereas OCN increase resulted in increased EE (Ferron et al. 2012). OCN decreases adiposity and increases adiponectin production in white fat cells (Ferron et al. 2008). Age-dependent changes in energy homeostasis are also consistent with changes in uOCN levels. In young male or female OI mice uOCN was increased and multiple measures of glucose/ insulin and $\mathrm{VO}_{2} / \mathrm{VCO}_{2}$ metabolism were affected. In older animals, OCN normalized and the metabolic indices became similar in OI and WT mice. Taken together, our data are consistent with the hypothesis that the increase in undercarboxylated OCN underlies the observed changes in whole body energy homeostasis in OI mice.

A similar metabolic phenotype may be present in humans with OI. A study on 30 children with OI found elevated body temperature, heart and respiratory rates, rate of oxygen consumption as well as heat production (Cropp \& Myers 1972). This was most evident in toddlers and pre-pubertal children, but not in adolescents and young adults (Cropp \& Myers 1972). It has also been noted that children with OI can have excessive sweating (potentially reflecting high EE) that diminishes after treatment with the anti-resorptive drug pamidronate (Glorieux et al. 1998, Åström \& Söderhäll 2002). Changes in body weight with age in OI patients demonstrate that in young children with OI it is common to observe low body weight for height, so that many OI children shorter than $110 \mathrm{~cm}$, or younger than 9-10 years are underweight (Aglan et al. 2012, Germain-Lee et al. 2016, Graff \& Syczewska 2017). However, after puberty and especially in adult patients, the trend is reversed with majority of OI patients presenting with normal to high weight for their height, and increasing numbers of overweight and obese patients (Watanabe et al. 2007, Chagas et al. 2012, Germain-Lee et al. 2016). Pamidronate treatment can also be associated with weight gain in some boys with OI (Zeitlin et al. 2003). Our mouse study suggests that OCN may be an important mediator of these changes. In humans, increased OCN levels correlate with improved glucose tolerance and insulin secretion and protect from obesity and metabolic syndrome (Pittas et al. 2009, Saleem et al. 2010). Thus, more studies are clearly needed to fully investigate the extent and consequences of heightened metabolic state in OI children.

It is important to note that there is a profound lack of baseline data on metabolic parameters in young animals. In fact, from $\sim 400$ Medline results for a query on the use of indirect calorimetry in mouse studies only 5 reports included 6 weeks old or younger mice. Moreover, we have found that changes in metabolism in OI animals occur in a sex-specific manner. Understanding the differences related to biological sex is critically important for the development of personalize therapeutic strategies. Although sexual dimorphism has been identified in OI patients (Zeitlin et al. 2003), and glucose homeostasis is well known for its substantial differences in males and females (Glucksmann 1974), only 7 from 313 OI animal model studies queried on Medline directly examined sexual dimorphism, and only 3 of 5 reports examining 
metabolic changes in young mice included both sexes in the study. This study advances our understanding of ageand sex-specific differences in mammalian metabolism, which is critical for development of pre-clinical animal models. Better understanding of age-and sex-specific changes in whole body energy homeostasis in children with OI will eventually help to address an unmet need of young OI patients, slow growth and low muscle mass, which are currently poorly understood and untreated.

In conclusion, our study suggests a novel contributor to the pathophysiology of OI-change in the metabolic state due to elevated levels of undercarboxylated OCN. We demonstrate that metabolic phenotype was most significant in young OI animals, corresponding to prepubertal growth in humans, and exhibited significant sexual dimorphism. Understanding the contribution of bone-driven systemic endocrine changes to functional performance of musculoskeletal system in OI will allow in developing the strategies to improve growth and muscle physiology in OI patients.

\section{Declaration of interest}

The authors declare that there is no conflict of interest that could be perceived as prejudicing the impartiality of the research reported.

\section{Funding}

Financial support was provided by the Canadian Institutes of Health Research (MOP-137091, MOP-133652 and PJT-152926), the Réseau de recherche en santé buccodentaire et osseuse, Faculty of Dentistry, McGill University, and Canada Research Chair program.

\section{Author contribution statement}

I B D and $\mathrm{S} V \mathrm{~K}$ designed the experiments, interpreted the results and prepared the manuscript; $\mathrm{F} \mathrm{R}$ and M F contributed to the experimental design, data analysis and interpretation; I B D, J T T and O E R performed the experiments; $D \mathrm{G}$ and $\mathrm{G} \mathrm{L}$ developed and validated the clustering algorithm. All authors read and approved the manuscript.

\section{Acknowledgements}

We are grateful to Xiaohong Liu, McGill University for performing metabolic cages experiments, to veterinary technicians Mia Esser, and Louise Marineau (Shriners Hospital for Children-Canada), and Melissa Marceau and Guylaine Gadoury (McGill University Health Center Research Institute) for help in running animal studies; to undergraduate students Turney McKee, Lilly Scott for help with data entry and proofreading, to Dr Monzur Murshed, McGill University for helpful discussions. We are grateful for the support by the McGill Mouse Metabolic Platform and the Centre for Bone and Periodontal Research.

\section{References}

Abdelaziz DM, Abdullah S, Magnussen C, Ribeiro-da-Silva A, Komarova SV, Rauch F \& Stone LS 2015 Behavioral signs of pain and functional impairment in a mouse model of osteogenesis imperfecta. Bone $\mathbf{8 1}$ 400-406. (doi:10.1016/j.bone.2015.08.001)

Aglan MS, Hosny L, El-Houssini R, Abdelhadi S, Salem F, ElBanna RAS, Awad SA, Zaki ME \& Temtamy SA 2012 A scoring system for the assessment of clinical severity in osteogenesis imperfecta. Journal of Children's Orthopaedics 6 29-35. (doi:10.1007/s11832-012-0385-3)

Åström E \& Söderhäll S 2002 Beneficial effect of long term intravenous bisphosphonate treatment of osteogenesis imperfecta. Archives of Disease in Childhood 86 356-364. (doi:10.1136/adc.86.5.356)

Brunetti G, Papadia F, Tummolo A, Fischetto R, Nicastro F, Piacente L, Ventura A, Mori G, Oranger A, Gigante I, et al. 2016 Impaired bone remodeling in children with osteogenesis imperfecta treated and untreated with bisphosphonates: the role of DKK1, RANKL, and TNF- $\alpha$. Osteoporosis International 27 2355-2365. (doi:10.1007/s00198016-3501-2)

Chagas CEA, Roque JP, Santarosa Emo Peters B, Lazaretti-Castro M \& Martini LA 2012 Do patients with osteogenesis imperfecta need individualized nutritional support? Nutrition 28 138-142. (doi:10.1016/j.nut.2011.04.003)

Chen F, Guo R, Itoh S, Moreno L, Rosenthal E, Zappitelli T, Zirngibl RA, Flenniken A, Cole W, Grynpas M, et al. 2014 First mouse model for combined osteogenesis imperfecta and ehlers-danlos syndrome. Journal of Bone and Mineral Research 29 1412-1423. (doi:10.1002/ jbmr.2177)

Cheung MS, Glorieux FH \& Rauch F 2009 Large osteoclasts in pediatric osteogenesis imperfecta patients receiving intravenous pamidronate. Journal of Bone and Mineral Research 24 669-674. (doi:10.1359/ jbmr.081225)

Cropp GJA \& Myers DN 1972 Physiological evidence of hypermetabolism in osteogenesis imperfecta. Pediatrics 49 375-391.

Daley E, Streeten EA, Sorkin JD, Kuznetsova N, Shapses SA, Carleton SM, Shuldiner AR, Marini JC, Phillips CL, Goldstein SA, et al. 2010 Variable bone fragility associated with an Amish COL1A2 variant and a knock-in mouse model. Journal of Bone and Mineral Research 25 247-261. (doi:10.1359/jbmr.090720)

Ducy P, Desbois C, Boyce B, Pinero G, Story B, Dunstan C, Smith E, Bonadio J, Goldstein S, Gundberg C, et al. 1996 Increased bone formation in osteocalcin-deficient mice. Nature 382 448-452. (doi:10.1038/382448a0)

Ferron M, Hinoi E, Karsenty G \& Ducy P 2008 Osteocalcin differentially regulates beta cell and adipocyte gene expression and affects the development of metabolic diseases in wild-type mice. PNAS $\mathbf{1 0 5}$ 5266-5270. (doi:10.1073/pnas.0711119105)

Ferron M, Wei J, Yoshizawa T, Del Fattore A, DePinho RA, Teti A, Ducy P \& Karsenty G 2010a Insulin signaling in osteoblasts integrates bone remodeling and energy metabolism. Cell 142 296-308. (doi:10.1016/j. cell.2010.06.003)

Ferron M, Wei J, Yoshizawa T, Ducy P \& Karsenty G 2010b An ELISAbased method to quantify osteocalcin carboxylation in mice. Biochemical and Biophysical Research Communications 397 691-696. (doi:10.1016/j.bbrc.2010.06.008)

Ferron M, McKee MD, Levine RL, Ducy P \& Karsenty G 2012 Intermittent injections of osteocalcin improve glucose metabolism and prevent type 2 diabetes in mice. Bone 50 568-575. (doi:10.1016/j. bone.2011.04.017)

Ferron M, Lacombe J, Germain A, Oury F \& Karsenty G 2015 GGCX and VKORC1 inhibit osteocalcin endocrine functions. Journal of Cell Biology 208 761-776. (doi:10.1083/jcb.201409111)

Forlino A, Cabral WA, Barnes AM \& Marini JC 2011 New perspectives on osteogenesis imperfecta. Nature Reviews Endocrinology 7 540-557. (doi:10.1038/nrendo.2011.81) http://joe.endocrinology-journals.org

DOI: $10.1530 / \mathrm{JOE}-17-0335$
๑ 2017 Society for Endocrinology Printed in Great Britain
Published by Bioscientifica Ltd 
Fulzele K \& Clemens TL 2012 Novel functions for insulin in bone. Bone 50 452-456. (doi:10.1016/j.bone.2011.06.018)

Germain-Lee EL, Brennen FS, Stern D, Kantipuly A, Melvin P, Terkowitz MS, Shapiro JR, Germain-Lee EL \& Shapiro JR 2016 Cross-sectional and longitudinal growth patterns in osteogenesis imperfecta: implications for clinical care. Pediatric Research 79 489-495. (doi:10.1038/pr.2015.230)

Glorieux FH, Bishop NJ, Plotkin H, Chabot G, Lanoue G \& Travers R 1998 Cyclic administration of pamidronate in children with severe osteogenesis imperfecta. New England Journal of Medicine 339 947-952. (doi:10.1056/NEJM199810013391402)

Glucksmann A 1974 Sexual dimorphism in mammals. Biological Reviews 49 423-475. (doi:10.1111/j.1469-185X.1974.tb01171.x)

Graff K \& Syczewska M 2017 Developmental charts for children with osteogenesis imperfecta, type I (body height, body weight and BMI). European Journal of Pediatrics 176 311-316. (doi:10.1007/ s00431-016-2839-y)

Kalajzic I, Terzic J, Rumboldt Z, Mack K, Naprta A, Ledgard F, Gronowicz G, Clark SH \& Rowe DW 2002 Osteoblastic response to the defective matrix in the osteogenesis imperfecta murine (oim) mouse. Endocrinology 143 1594-1601. (doi:10.1210/endo.143.5.8807)

Karsenty G \& Ferron M 2012 The contribution of bone to wholeorganism physiology. Nature $\mathbf{4 8 1} 314-320$. (doi:10.1038/ nature10763)

Kozloff KM, Carden A, Bergwitz C, Forlino A, Uveges TE, Morris MD, Marini JC \& Goldstein SA 2004 Brittle IV mouse model for osteogenesis imperfecta IV demonstrates postpubertal adaptations to improve whole bone strength. Journal of Bone and Mineral Research 19 614-622. (doi:10.1359/JBMR.040111)

Lacombe J, Karsenty G \& Ferron M 2013 In vivo analysis of the contribution of bone resorption to the control of glucose metabolism in mice. Molecular Metabolism 2 498-504. (doi:10.1016/j. molmet.2013.08.004)

Lee NK, Sowa H, Hinoi E, Ferron M, Ahn JD, Confavreux C, Dacquin R, Mee PJ, McKee MD, Jung DY, et al. 2007 Endocrine regulation of energy metabolism by the skeleton. Cell 130 456-469. (doi:10.1016/j. cell.2007.05.047)

Li H, Jiang X, Delaney J, Franceschetti T, Bilic-Curcic I, Kalinovsky J, Lorenzo JA, Grcevic D, Rowe DW \& Kalajzic I 2010 Immature Osteoblast Lineage Cells Increase Osteoclastogenesis in Osteogenesis Imperfecta Murine. American Journal of Pathology 176 2405-2413. (doi:10.2353/ajpath.2010.090704)

Mera P, Laue K, Wei J, Berger JM \& Karsenty G 2016 Osteocalcin is necessary and sufficient to maintain muscle mass in older mice. Molecular Metabolism 5 1042-1047. (doi:10.1016/j. molmet.2016.07.002)

Palomo T, Glorieux FH, Schoenau E \& Rauch F 2016 Body Composition in Children and Adolescents with Osteogenesis Imperfecta. Journal of Pediatrics 169 232-237. (doi:10.1016/j.jpeds.2015.10.058)
Pittas AG, Harris SS, Eliades M, Stark P \& Dawson-Hughes B 2009 Association between serum osteocalcin and markers of metabolic phenotype. Journal of Clinical Endocrinology and Metabolism 94 827-832. (doi:10.1210/jc.2008-1422)

Pouliot-Laforte A, Veilleux LN, Rauch F \& Lemay M 2014 Validity of an accelerometer as a vertical ground reaction force measuring device in healthy children and adolescents and in children and adolescents with osteogenesis imperfecta type I. Journal of Musculoskeletal and Neuronal Interactions 14 155-161.

Rauch F, Travers R, Parfitt AM \& Glorieux FH 2000 Static and dynamic bone histomorphometry in children with osteogenesis imperfecta. Bone 26 581-589. (doi:10.1016/S8756-3282(00)00269-6)

Rauch F, Lalic L, Roughley P \& Glorieux FH 2010 Relationship between genotype and skeletal phenotype in children and adolescents with osteogenesis imperfecta. Journal of Bone and Mineral Research 25 1367-1374. (doi:10.1359/jbmr.091109)

Rencher AC \& Christensen WF 2012 Methods of Multivariate Analysis. Third edn. Hoboken, NJ, USA: John Wiley \& Sons.

Roschger A, Roschger P, Keplingter P, Klaushofer K, Abdullah S, Kneissel M \& Rauch F 2014 Effect of sclerostin antibody treatment in a mouse model of severe osteogenesis imperfecta. Bone 66 182-188. (doi:10.1016/j.bone.2014.06.015)

Saleem U, Mosley TH \& Kullo IJ 2010 Serum osteocalcin is associated with measures of insulin resistance, adipokine levels, and the presence of metabolic syndrome. Arteriosclerosis, Thrombosis, and Vascular Biology 30 1474-1478. (doi:10.1161/ATVBAHA.110.204859)

Sinder BP, Salemi JD, Ominsky MS, Caird MS, Marini JC \& Kozloff KM 2015 Rapidly growing Brtl/+ mouse model of osteogenesis imperfecta improves bone mass and strength with sclerostin antibody treatment. Bone 71 115-123. (doi:10.1016/j.bone.2014.10.012)

Uveges TE, Collin-Osdoby P, Cabral WA, Ledgard F, Goldberg L, Bergwitz C, Forlino A, Osdoby P, Gronowicz GA \& Marini JC 2008 Cellular mechanism of decreased bone in Brtl mouse model of OI: imbalance of decreased osteoblast function and increased osteoclasts and their precursors. Journal of Bone and Mineral Research 23 1983-1994. (doi:10.1359/jbmr.080804)

Veilleux LN, Pouliot-Laforte A, Lemay M, Cheung MS, Glorieux FH \& Rauch F 2015 The functional muscle-bone unit in patients with osteogenesis imperfecta type I. Bone 79 52-57. (doi:10.1016/j.bone.2015.05.019)

Ward JH Jr 1963 Hierarchical grouping to optimize an objective function. Journal of the American Statistical Association 58 236-244. (doi:10.1080/ 01621459.1963.10500845)

Watanabe G, Kawaguchi S, Matsuyama T \& Yamashita T 2007 Correlation of scoliotic curvature with Z-score bone mineral density and body mass index in patients with osteogenesis imperfecta. Spine $\mathbf{3 2}$ 488-494. (doi:10.1097/BRS.0b013e31811ec2d9)

Zeitlin L, Fassier F \& Glorieux FH 2003 Modern approach to children with osteogenesis imperfecta. Journal of Pediatric Orthopaedics B 12 77-87. (doi:10.1097/01.bpb.0000049567.52224.fa)

Received in final form 11 July 2017

Accepted 17 July 2017

Accepted preprint published online 17 July 2017 http://joe.endocrinology-journals.org

DOI: 10.1530/JOE-17-0335
๑) 2017 Society for Endocrinology Printed in Great Britain
Published by Bioscientifica Ltd. 